\begin{tabular}{|c|c|}
\hline Title & $\begin{array}{l}\text { Water Transport and PEFC Performance with Different Interface Structure between Micro-Porous Layer and Catalyst } \\
\text { Layer }\end{array}$ \\
\hline Author(s) & A oyama, Y usuke; Suzuki, Kengo; Tabe, Y utaka; Chikahisa, T akemi; T anuma, Toshihiro \\
\hline Citation & $\begin{array}{l}\text { Journal of the electrochemical society, 163(5), F359-F366 } \\
\text { https://doi.org/10.1149/2.0451605jes }\end{array}$ \\
\hline Issue Date & 2016-04-14 \\
\hline Doc URL & http:/hdl.handle.net/2115/61205 \\
\hline Rights & $\begin{array}{l}\text { (O) The Electrochemical Society, Inc. 2016. All rights reserved. Except as provided under U.S. copyright law, this work } \\
\text { may not be reproduced, resold, distributed, or modified without the express permission of The Electrochemical Society } \\
\text { (ECS). The archival version of this work was published in J. Electrochem. Soc.,volume 163, issue 5, pp.F359-F366, } \\
2016 \text {. }\end{array}$ \\
\hline Rights(URL) & http://reativecommons.org/icenses/by/4.0/ \\
\hline Type & article \\
\hline File Information & J. Electrochem. Soc.-2016-A oyamaF359-66.pdf \\
\hline
\end{tabular}

Instructions for use 


\title{
Water Transport and PEFC Performance with Different Interface Structure between Micro-Porous Layer and Catalyst Layer
}

\author{
Yusuke Aoyama, ${ }^{\mathrm{a}, \mathrm{z}}$ Kengo Suzuki, ${ }^{\mathrm{a}}$ Yutaka Tabe, ${ }^{\mathrm{a}}$ Takemi Chikahisa, ${ }^{\mathrm{a}}$ and Toshihiro Tanuma ${ }^{\mathrm{b}}$ \\ ${ }^{a}$ Division of Energy and Environmental Systems, Graduate School of Engineering, Hokkaido University, Sapporo, \\ Hokkaido 060-8628, Japan \\ ${ }^{b}$ Asahi Glass Co., Ltd. Research Center, Kanagawa-ku, Yokohama, Kanagawa 221-8875, Japan
}

\begin{abstract}
For interfaces between micro-porous layers (MPL) and catalyst layers (CL) made by the gas diffusion electrode (GDE) method, a seamless interface without gaps, shows better performance than that of cells with an interface made by the decal transfer method. With the decal transfer method, the MPL is simply hot-pressed to the CL-membrane assembly. This study investigates the effect of interface structure on cell performance and water transport in the MPL. Water distribution in cross sections of multiple layers were observed by a freezing method, where the cell is cooled below freezing temperature in short time and the water was observed in ice form by Cryo-SEM. The results show that a membrane electrode assembly (MEA) using the GDE method improves cell performance at high current densities. Direct observations by the freezing method and cryo-SEM show that there is no water accumulation at the MPL/CL interface made by the GDE method, while water accumulates at the interface made by the decal method. Other observations show that the water amount inside the MPL increases similarly in the two types of MEA when lowering the temperature, and the difference between the two types of MEA was only the water amount in the interface.

(C) The Author(s) 2016. Published by ECS. This is an open access article distributed under the terms of the Creative Commons Attribution 4.0 License (CC BY, http://creativecommons.org/licenses/by/4.0/), which permits unrestricted reuse of the work in any medium, provided the original work is properly cited. [DOI: 10.1149/2.0451605jes] All rights reserved.
\end{abstract}

Manuscript submitted September 29, 2015; revised manuscript received January 5, 2016. Published January 27, 2016. This was Paper 1543 presented at the San Francisco, California, Meeting of the Society, October 27-November 1, 2013.

Polymer electrolyte fuel cells (PEFCs) are promising power sources for next generation vehicles, motorcycles, and residential cogeneration systems (the so-called combined heat and power; $\mathrm{CHP}$ ). However, there is considerable potential for improvements in the performance for the PEFC to become practical in many other applications. Water flooding, the blockage of the gas supply to the reaction area by accumulation of water, is one of the major issues with the PEFC, as cell performance deteriorates significantly under high current density conditions. Micro-porous layers (MPLs), typically consisting of carbon black and a hydrophobic polymer, have been demonstrated to be an important component in improving the water management of the PEFC.

The effect of a hydrophobic MPL on the water transport mechanism in the cell has been investigated by computational and experimental studies, and these studies have suggested that the MPL removes produced water from the reaction area. ${ }^{1-5}$ Weber et al. and Pasaogullari et al. reported that the MPL reduces the amount of water passing through the cathode side of the gas diffusion layer (GDL) by increasing the water flow from cathode to anode. ${ }^{1,2}$ Gostick et al. and $\mathrm{Lu}$ et al. suggested that cracks in the MPL are the pathways of the water discharge, and that this results in reductions in the water saturation in the GDL. ${ }^{3,4}$ Owejan et al. investigated water transport in the MPL by measuring the performance of cells with various types of MPL, and proposed that the MPL prevents the water in the GDL from contacting with and forming a water film on the catalyst layer (CL) surface. ${ }^{5}$ They also investigated the water vapor transport capacity through the MPL driven by the saturation pressure gradient in the cathode diffusion layer due to the temperature gradient, and demonstrated that the water vapor flux can remove produced water even at high current densities under normal operating conditions because the saturation pressure gradient is sufficient for the water removal.

Other than the studies of the functioning of the MPL, the interface gap between the cathode side MPL and CL has become a focus for improving cell performance and water management of PEFC. ${ }^{6-10}$ Hizir et al. reported that the gaps at the MPL/CL interface may act as water pooling sites and prevent the reactant gases from reaching active sites in the CL. ${ }^{6}$ Kalidindi et al. developed a two-dimensional model to simulate the two phase transport within the gaps at the MPL/CL interface, and investigated the influences of these gaps on the cell performance. ${ }^{7}$ The simulations there showed that the interface

${ }^{\text {z} E-m a i l: ~ y . a o y a m a @ e n g . h o k u d a i . a c . j p ~}$ gaps between the MPL and the CL significantly reduce the limiting current density as compared with a perfect interface contact without gaps because of the accumulation of water at the gaps. Zenyuk et al. calculated the surface roughness of the MPL and the average contact resistance between the MPL and the CL, and also modeled water retention curves based on the void size distributions of the interface. ${ }^{8}$ They showed that uneven interface contact between the MPL and the CL due to cracks results in increases in water saturation. Bajpai et al. estimated the impact of the MPL/CL interface surface morphology on the local ohmic, thermal, and mass transport losses. ${ }^{9}$ Swamy et al. reported that the contact resistance of the MPL/CL interface under the channels is higher than under the lands because of the different compression pressures under channels and lands..$^{10}$

To further verify the results of these simulation analyses and discuss the influence of interface gaps on performance and water transport in the cell, visualization studies focusing on water transport at the MPL/CL interface need to be conducted. There are a variety of methods to visualize how the produced water is removed from the reaction area, including optical visualization with transparent cells, ${ }^{11}$ scanning electron microscopy (SEM), ${ }^{12} \mathrm{X}$-ray radiography, ${ }^{13-16}$ and neutron radiography. ${ }^{17}$ Sasabe et al. visualized water accumulation and discharge in an operating cell by a soft X-ray radiographic technique, and suggested that the MPL prevents the accumulation of water in the substrate layer. ${ }^{13}$ Deevanhxay et al. observed water accumulation and transport in the cathode side MPL and GDL, and suggested that the water generated from the cell reactions was transported to the GDL mainly through cracks in the MPL. ${ }^{14}$ Hartnig et al. estimated that the MPL holds very little water even at high current density operation by using synchrotron X-ray radiography, and suggested that the produced water diffuses through the MPL as vapor and condenses in hydrophilic areas of the GDL. ${ }^{16}$ Hatzell et al. quantified the water transport in the diffusion media with the neutron imaging, and suggested that the water transport is induced by phase change induced flow because liquid water cannot seep out into the small pores in the hydrophobic MPL. ${ }^{17}$

Among this research there is, however, no research that shows direct images of the inside of the MPL or of the interface between the MPL and CL with high spatial resolution. The authors have developed a freezing method to visualize the distribution of water in cells directly by cryo-SEM. ${ }^{18}$ By using the cryo-SEM for the observations, the water distribution inside the MPL can be visualized at high spatial resolutions, at the micro-nano scale. The authors observed the through-plane (direction perpendicular to the membrane electrode 
assembly (MEA) surface) distribution of water inside the cathode side MPL to determine the phase of the produced water in the MPL. The results indicated that the produced water passes through the MPL as vapor under usual PEFC operating conditions while it condenses inside the MPL under low cell temperature operation. The authors also observed the in-plane (direction parallel to the MEA surface) water distribution on the CL surface to understand the mechanism of the MPL suppression of water flooding. ${ }^{19}$ The results indicated that water accumulation at the CL surface increases with increasing current density, and the addition of the MPL could suppress water accumulation at the CL surface as a result of the finer contact with the CL.

Tanuma et al., one of the authors of this paper, investigated the effect of differences in cathode MPL/CL interface fabrication methods (decal transfer method, gas diffusion electrode (GDE) method, and membrane coating method) on cell performance under various operating conditions..$^{20}$ The authors also investigated the effect of the MPL/CL interface, and the results showed that an MEA made by the GDE method increases the cell voltage under wet conditions over those of an MEA made with the decal method at specific temperature conditions. ${ }^{19}$ These results suggested that a smooth MPL/CL interface without gaps could be expected to prevent water accumulation and so improve cell performance.

The study here observes the through-plane water distribution in the vicinity of the cathode side MPL to understand the mechanism of the increase in cell performance of a seamless MPL/CL interface without gaps. Two types of MEA with different MPL/CL interfaces were used. One MEA is produced by the GDE and the other by the decal transfer method. The freezing method and cryo-SEM ${ }^{18}$ were used for the direct observations. The freezing method immobilizes the water in the cell as ice by rapidly freezing the cell after steady-state operation is achieved, and the ice can be visualized with high spatial resolution by using the cryo-SEM. By comparing the cell performance and water distribution of the two types of MEA, the effect of differences in the structure of the interface between the MPL and CL on the cell performance and water transport is discussed.

\section{Experimental}

Experimental apparatus. - This study used a small sized single cell with an active area of $1.8 \mathrm{~cm}^{2}(0.9 \mathrm{~cm} \times 2.0 \mathrm{~cm})$ to allow the cell to be frozen and disassembled rapidly with the freezing method. The separator, which was made of gilded copper and integrated with an electricity collector, had five straight flow channels and four lands. The lengths and widths of the channels and lands were $11.5 \mathrm{~mm}$ and 1.0 $\mathrm{mm}$, respectively, and the channel depth was $0.5 \mathrm{~mm}$. The separators and the MEA were enclosed by stainless-steel end-plates.

Two types of MEA with different MPL/CL interfaces were used: one with a smooth interface without gaps and one with a conventional hot-pressed interface. The former is made by directly coating catalyst ink on the MPL, and this fabrication method is termed the gas diffusion electrode (GDE) method. The latter is made by attaching the MPL to the CL by hot-pressing, and this conventional fabrication method is known as the decal transfer method. These fabrication procedures for the MEA can be summarized as shown in Fig. $1 .{ }^{20}$ In the GDE method (top two steps in Fig. 1), the cathode CL was formed by directly coating catalyst ink on the cathode MPL surface by a wire-rod coater, to form the GDE of the cathode CL, MPL, and GDL. The anode side MPL/CL interface was fabricated by the decal transfer method. The MEA were assembled by hot-pressing the membrane with the anode CL, the anode GDL with the MPL, and the cathode GDE. In the decal transfer method (bottom three steps in Fig. 1), the CL was made by wire-rod coating the catalyst ink on the substrate (ethylene tetrafluoroethylene (ETFE) film). Then, the CL was hot-pressed on the membrane, and a catalyst coated membrane (CCM) was formed. Finally, the MEA was assembled by hot-pressing $\left(160^{\circ} \mathrm{C}, 3.0 \mathrm{MPa}\right.$, $2 \mathrm{~min}$ ) of the CCM and GDL with the MPL. The MEA used in the experiments were produced by Asahi Glass Co., Ltd.

Experimental methods.-Pure hydrogen and air/oxygen were used as the anode and cathode side reactant gases, respectively. These reactant gases were supplied in a co-flow, and were humidified by bubblers. The temperature of the reactant gases and bubblers were controlled by ribbon heaters and thermocouples. The cell was set in a thermostatic chamber (HITACHI, EC-25MTP controllable temperature range of -40 to $100^{\circ} \mathrm{C}$ ), and the cell temperature was controlled by the chamber temperature. The cell resistance was measured by an alternating impedance meter at $1 \mathrm{kHz}$ (TSURUGA, model 3566), and the cell voltage, resistance, and temperatures (cell, supply gases, and bubbler) were recorded.

To investigate the impact of the MPL/CL interface on the cell performance, polarization curves, oxygen gain, and time series changes in the voltages under constant current density operation were measured.

\section{Gas diffusion electrode (GDE) method}

1. Wire-rod coating to MPL

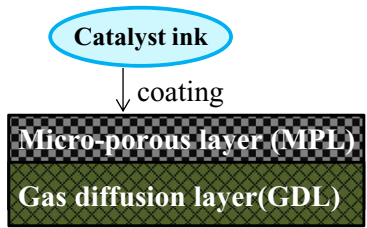

2. Hot-pressing to membrane

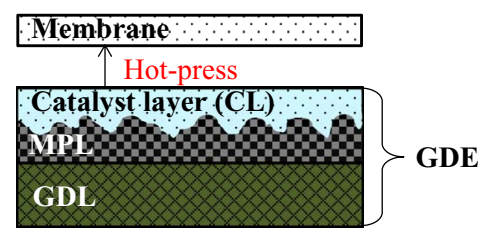

\section{Decal transfer method}

1. Wire-rod coating to substrate

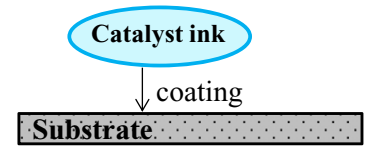

2. Decal transfer to membrane by hot-press

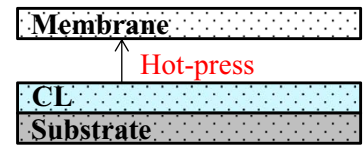

3. Assemble the MEA by hot-press

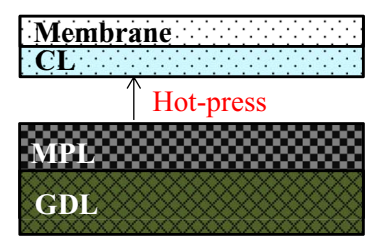

Figure 1. Cathode fabrication methods: the gas diffusion electrode (GDE) method (top) and the decal transfer method (bottom). 
(a)

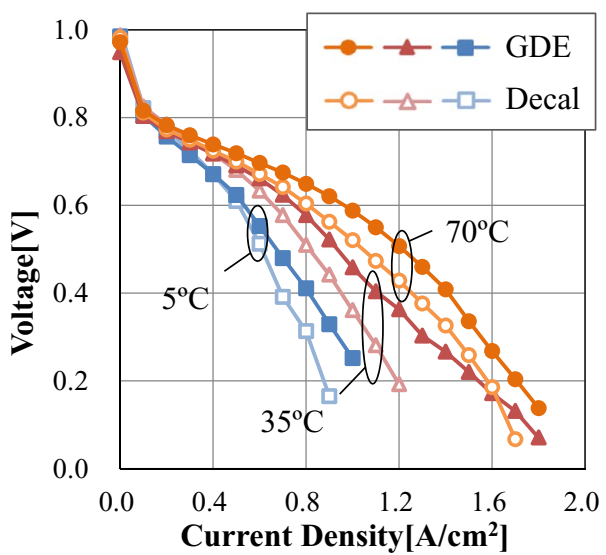

(c)

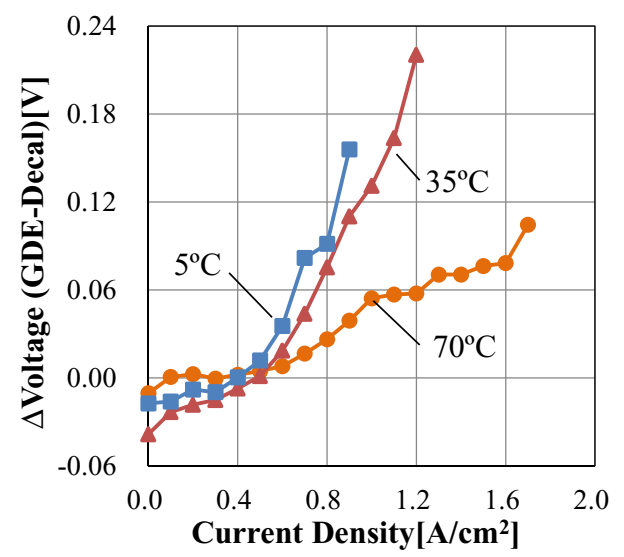

(b)

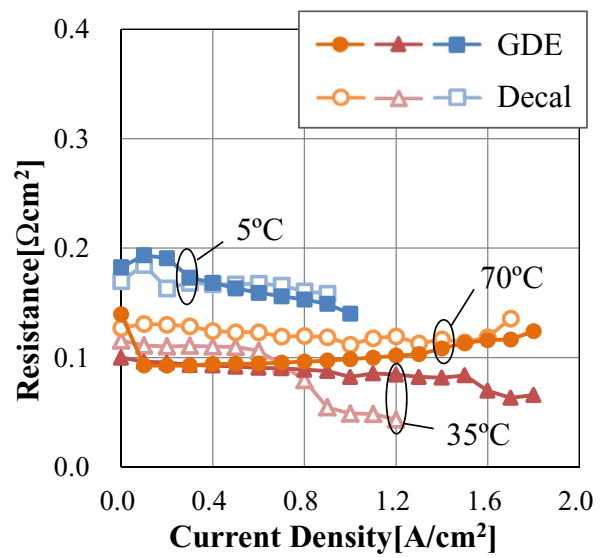

(d)

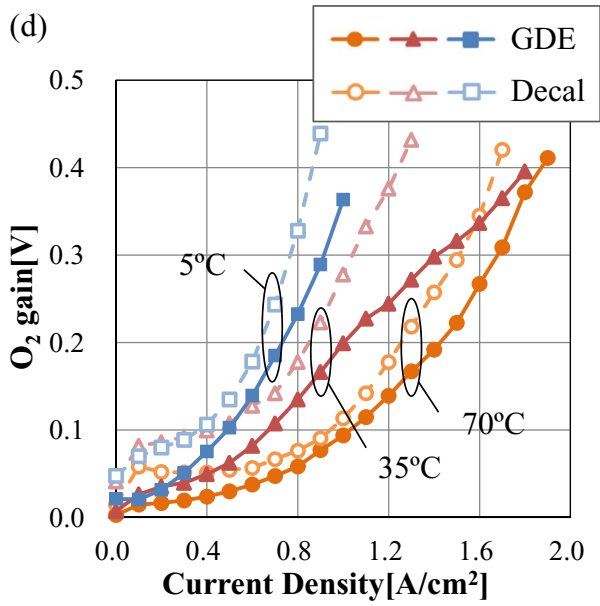

Figure 2. Performance of the MEA using the GDE and decal transfer methods. (a) polarization curves, (b) resistance, (c) differences of the IR-corrected cell voltage, and (d) oxygen gain.

The cell performance was measured under three operating conditions: a cell temperature of $70^{\circ} \mathrm{C}$ and bubbler temperatures of $65^{\circ} \mathrm{C}(81 \%$ relative humidity ( $\mathrm{RH})$ ), a cell temperature of $35^{\circ} \mathrm{C}$ and bubbler temperatures of $35^{\circ} \mathrm{C}(100 \% \mathrm{RH})$, and a cell temperature of $5^{\circ} \mathrm{C}$ with dry gases. The bubbler temperatures were set as identical for both the anode and cathode gases. All these conditions are regarded as wet conditions; even the $5^{\circ} \mathrm{C}$ operation with dry gas causes flooding because the temperature is much lower than in usual operation. ${ }^{18}$ For all operating conditions, the flow rates of the anode hydrogen and the cathode air/oxygen were set to 100 and 400 standard cc min ${ }^{-1}$ (SCCM); these correspond to stoichiometric ratios of 11 and 19 for the anode and cathode gases at $0.7 \mathrm{~A} \mathrm{~cm}^{-2}$, respectively. The stoichiometric ratios are quite high due to the small reaction area, but the flow speed around $2.7 \mathrm{~m} \mathrm{~s}^{-1}$ for cathode is not high. In the polarization curve measurements, the current density was maintained at each measurement point for 2 minutes, to reach a steady state, and the cell was regarded to have shut down if the cell voltage fluctuated widely and was not stabilized within the 2 minutes. The oxygen gain was calculated as the difference in polarization curves between the air and oxygen operations, when the cell voltages were corrected for the ohmic loss. The constant current density operation was carried out at $0.7 \mathrm{~A} \mathrm{~cm}^{-2}$. The current density was increased from $0.0 \mathrm{~A} \mathrm{~cm}^{-2}$ to $0.7 \mathrm{~A} \mathrm{~cm}^{-2}$ over 5 minutes and then maintained at $0.7 \mathrm{~A} \mathrm{~cm}^{-2}$ for 1 hour.

In this study, the freezing method and cryo-SEM ${ }^{18}$ were used for the visualization of the water distributions in the vicinity of the cathode side MPL at high spatial resolutions. After achieving constant current density operation, the cell was shut down and immediately cooled at $-40^{\circ} \mathrm{C}$ in the thermostatic chamber to arrest the water in the cell in the position where it was at the time of the shutdown. In a separate experiment, the authors have confirmed that the water moves little during the cooling process. ${ }^{21}$ It was also confirmed that ice is not generated during freezing when there is no condensed water before cooling, even if MEA is hydrated. The cell with the frozen water was disassembled in the thermostatic chamber at $-40^{\circ} \mathrm{C}$, and the MEA was cooled further in liquid nitrogen to prevent sublimation of the ice during the preparation for the observations. The MEA was cut into pieces perpendicular to the gas flow direction in liquid nitrogen and set on a sample holder. The samples were moved from the liquid nitrogen to the preparation chamber at $-100^{\circ} \mathrm{C}$ in the cryo-SEM (JEOL, JSM$6701 \mathrm{~F}$ with Gatan, ALTO2500) and cut by a cooled knife. The cut surface of the sample was coated with Au-Pd for clear observations and prevention of sublimation of the ice. The sample was moved to the sample chamber of the cryo-SEM at $-150^{\circ} \mathrm{C}$ and observed with an acceleration voltage of $5 \mathrm{kV}$.

\section{Results and Discussion}

Effect of the MPL/CL interface structure on the cell performance.-The polarization curves and resistance of the cells using the GDE and decal transfer method are shown in Figs. 2a and $2 \mathrm{~b}$. The voltages of the cell using the GDE method are higher than those using the decal transfer method at high current densities at all operating conditions (Fig. 2a). This result is consistent with the results by Tanuma et al. which were obtained by using a single cell with an active area of $25 \mathrm{~cm}^{2}$ in wet conditions $\left(80^{\circ} \mathrm{C}, 100 \% \mathrm{RH}\right){ }^{20}$ The 
(a)

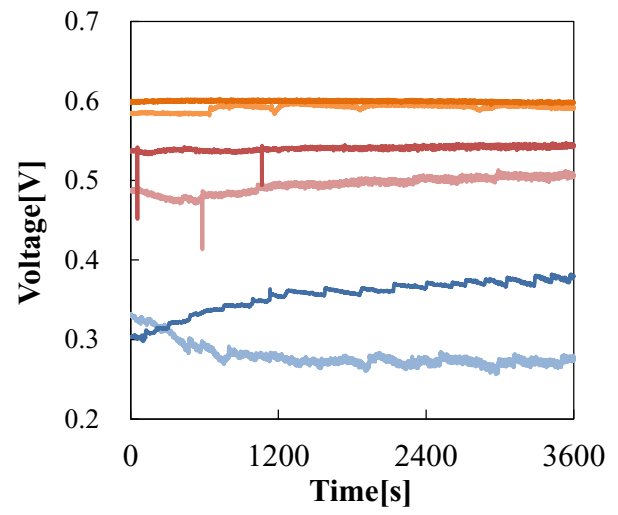

(b)

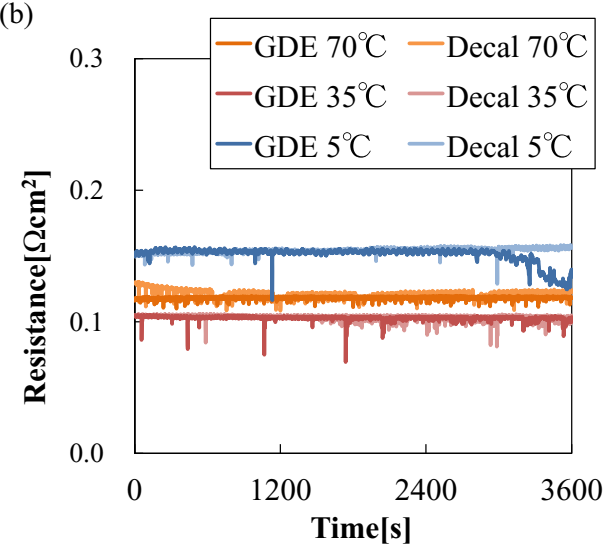

Figure 3. Changes in the (a) cell voltage and (b) resistance at the constant current density of $0.7 \mathrm{~A} \mathrm{~cm}^{-2}$ at $70^{\circ} \mathrm{C}, 35^{\circ} \mathrm{C}$, and $5^{\circ} \mathrm{C}$.

limiting current densities of the cell using the GDE method are higher than those using the decal transfer method. The differences in the cell voltages of the two types of MEA increase as the cell temperature decreases. There are no significant differences in the resistance of the two types of MEA under any of the operating temperatures (Fig. 2b).

Figure $2 \mathrm{c}$ shows the differences in the IR-corrected voltage of the cell using the GDE and decal transfer methods. Under low current density conditions, there is no significant difference in the voltage of the two types of MEA. The differences in voltages become larger as the current density increases, with larger differences in the $35^{\circ} \mathrm{C}$ and $5^{\circ} \mathrm{C}$ operation. In the $5^{\circ} \mathrm{C}$ operation, the voltage gap between the two types of MEA is almost four times larger than that in the $70^{\circ} \mathrm{C}$ operation at the current density of $0.9 \mathrm{~A} \mathrm{~cm}^{-2}$ as seen in Fig. 2c. This result shows that the performance of the cell using the GDE method decreases slightly, compared to the decal transfer method with significantly deterioration, in the low temperature operation.

To investigate the effect of the difference in interface structure and cell temperature on the oxygen transport in the cell, the oxygen gain was measured and is plotted in Fig. 2d. The oxygen gain indicates the oxygen transport resistance in the cell, which is analyzed by the difference in the IR-corrected cell voltage in air/oxygen operation, and a larger oxygen gain means a higher concentration overvoltage. The oxygen gains increase as current densities become higher, and the oxygen gains of the MEA using the GDE method are lower than that using the decal transfer method in all operating conditions. The results suggest that the MEA using the GDE method is less affected by the concentration overvoltage, and that the voltage difference in Fig. $2 \mathrm{c}$ is induced by the concentration overvoltage. All the data were for wet conditions, and it appears that the water flooding caused the concentration overvoltages. This suggests that the MEA using the GDE method suppresses the water flooding, and may play a role in reducing the voltage drop at higher current densities. The differences in the oxygen gain of the two types of MEA increase as cell temperature becomes lower. In the $5^{\circ} \mathrm{C}$ operation, the oxygen gain becomes almost ten times larger than that in the $70^{\circ} \mathrm{C}$ operation at the current density of $0.9 \mathrm{~A} \mathrm{~cm}^{-2}$. This result suggests that the oxygen gain of the MEA using the GDE method is less affected by cell temperature than that using the decal transfer method. In conclusion, it is suggested that the MEA using the GDE method can prevent deterioration of the cell performance by suppressing water flooding even under extreme operating conditions like the $5^{\circ} \mathrm{C}$ operation.

Figures $3 \mathrm{a}$ and $3 \mathrm{~b}$ show the results of 1 hour of constant current density operation for the cells with MEA made by the GDE and decal transfer methods: (a) plots the cell voltages, and (b) the cell resistance, here the current density was $0.7 \mathrm{~A} \mathrm{~cm}^{-2}$ for all the cell temperature conditions. The differences in the cell voltages between the MEA fabrication methods become larger as the cell temperature decreases, similar to the voltage differences shown in Fig. 2a. The voltages with the GDE cells are higher and more stable than with the decal transfer method under these operating conditions. The cell resistances for the GDE and decal transfer method cells are similar at all operating conditions here. These results support the suggestion that the interface between the MPL and CL made by the GDE method prevents the increase of concentration overvoltage caused by water flooding.

Cryo-SEM observations of ice distributions in the vicinity of the MPL under the ordinary condition at $70^{\circ} \mathrm{C}$.- - Figures $4 \mathrm{a}$ and $4 \mathrm{~b}$ show SEM images of the interface between the MPL and CL made by (a) the GDE and (b) the decal transfer methods before cell operation. The seamless interface made by the GDE method can hardly be distinguished, and it is much less visible than the conventional hotpressed interface made by the decal transfer method. The images here suggest that the GDE method realizes seamless interfaces without gaps. The porous structure of the MPL is clearly observed, and the mean pore diameter is smaller than $0.5 \mu \mathrm{m}$ as also reported by Nam et al. ${ }^{12}$ for both MEA fabrication methods. Other observation results showed that there are no apparent differences in the thickness and structure of the MPL and CL with the two MEA fabrication methods here. The structure of the MPL is similar to that of the CL as both layers are composed of carbon black.

To elucidate the mechanism working to reduce concentration overvoltage between the two fabrication methods, the water distribution in the cell was observed by the freezing method and cryo-SEM. Figures $5 \mathrm{a}-5 \mathrm{~d}$ show cryo-SEM images of the cathode side interface between the MPL and CL after operating the cell for 1 hour. The current density, cell temperature, and relative humidity of the gases were $0.7 \mathrm{~A}$ $\mathrm{cm}^{-2}, 70^{\circ} \mathrm{C}$, and $81 \%$, an ordinary operating condition. Figures $5 \mathrm{a}$ and $5 \mathrm{~b}$ are images of the interfaces under the gas flow channels of cells made by the GDE and the decal transfer method, respectively. There is no ice at the interface made by the GDE method (Fig. 5a). At the interface made by the decal transfer method in Fig. 5b, an 8 (a)

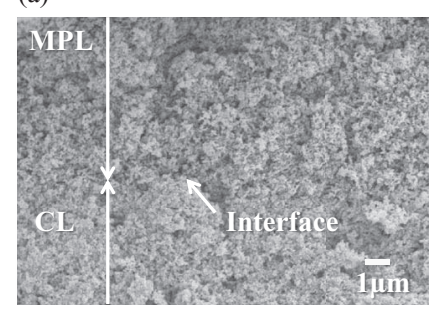

(b)

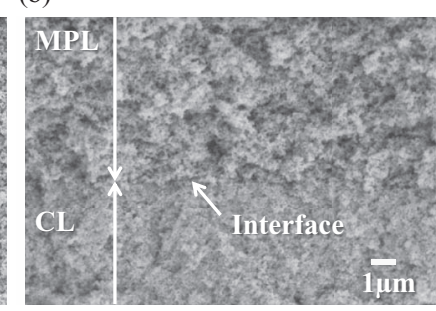

Figure 4. SEM images of the cross-sections of the cathode side of the MPL/CL interface made by (a) the GDE method and (b) the decal transfer method. 

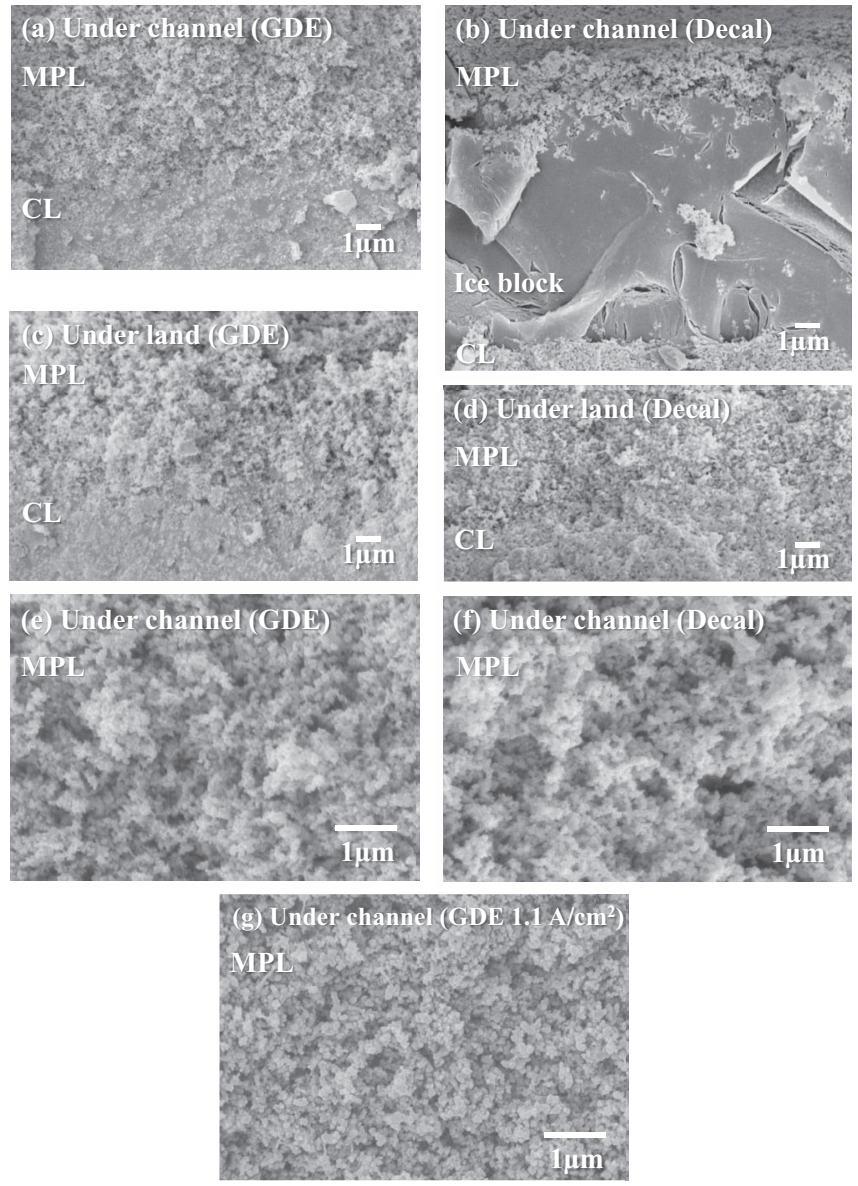

Figure 5. Cryo-SEM images of cross-sections of the cathode side MEA after the $70^{\circ} \mathrm{C}$ operation. (a) MPL/CL interface under a channel made by the GDE method, (b) MPL/CL interface under a channel made by the decal transfer method, (c) MPL/CL interface under a land made by the GDE method, (d) MPL/CL interface under a land made by the decal transfer method, (e) inside the MPL under a channel of the MEA made by the GDE method, (f) inside the MPL of the MEA under a channel made by the decal transfer method and $(\mathrm{g})$ inside the MPL under a channel of the MEA made by the GDE method after the 1 hour of operation at $1.1 \mathrm{~A} \mathrm{~cm}^{-2}$.

to $9 \mu \mathrm{m}$ thick ice layer can be observed; this is a typical image of the ice distribution at the interface under the channels when using the MEA made by the decal transfer method. There were ice layers under the channels at all points observed, while the thickness of the ice varied somewhat among the observation points. The authors have confirmed similar ice layers in many other MEA made by the decal transfer method. No such large gap was observed before the cell operation (Fig. 4b), and the water may be assumed to have expanded the interface gaps, allowing the accumulation of large amounts of water. Figures $5 \mathrm{c}$ and $5 \mathrm{~d}$ are images of the interfaces under lands made by the GDE and the decal transfer method, respectively. Under the lands, no ice layer can be observed at the MPL/CL interface made by both the GDE and decal transfer methods. In the CL there are many places filled with ice, which appears as a smooth surface with slightly dark regions as seen in the lower part of Figs. 5a-5d. The observations of the full CL showed that the ice distributes relatively uniformly from the membrane side to the MPL side at all observation points in both fabrication methods.

Figures $5 \mathrm{e}$ and $5 \mathrm{f}$ are images inside the cathode side MPL under channels made by the GDE and the decal transfer method after 1 hour of operation of the cell. The pictures inside the MPL are similar under both the channels and lands, and there is no ice inside the MPL with the porous structure similar to the situation before the operation.
Figure $5 \mathrm{~g}$ is also an image inside the MPL under the channels of the MEA using the GDE method, here the current density for the 1 hour operation is $1.1 \mathrm{~A} \mathrm{~cm}^{-2}$. Even under such a higher current density condition, there is no ice inside the MPL at the $70^{\circ} \mathrm{C}$ operation. These observed results suggest that the produced water passes through the MPL in vapor form under ordinary operating condition regardless of the interface fabrication method as the vapor transport is driven by the saturation pressure gradient for the temperature difference between the MPL. Further, the results of Figs. 5e and 5g suggest that water distribution inside the MPL is unaffected by the current density. This result is in line with the suggestion of Owejan et al.: water transport through the MPL by vapor is not affected by the current density because the water transport capacity is considered to be determined by the ratio of the released heat flux to the vapor flux, and both of these fluxes are proportional to the current density. ${ }^{5}$

These observations show that the interface made by the GDE method can prevent water accumulation at the MPL/CL interface under the channels, unlike the interface made by the decal transfer method. The difference of water accumulation in the two types of MEA is clearly shown under the channels, while there is little difference at the interfaces under the lands. One possible explanation for this water distribution is the difference in contact pressure between under lands and channels. The contact pressure on the CL surface tends to concentrate under the land regions, and the CL surface under the channels is under less pressure. In the case of the MEA using the decal transfer method, produced liquid water may expand the interface due to the lower contact pressure, allowing the accumulation of large amounts of water. Under the land regions, the interface gaps cannot expand because the interface is pressed by the land, and water does not accumulate at the interface. In the case of the MEA using the GDE method, there is no ice layer at the interface under both channels and lands. This result shows that water does not accumulate at the interface even in the low pressure regions under the channels, if the GDE method is applied. Since the GDE method can make a seamless interface without gaps between the MPL and CL, the water appears not to be able to accumulate at the interface even when the contact pressure is weak. Since there is no ice inside the MPL at any of the interface fabrication methods and current densities, the accumulation of water at the MPL/CL interface under the channels can be regarded as one of the major causes of the increase in the concentration overvoltage at high current densities. From these results, interfaces made by the GDE method appear to reduce the increase in concentration overvoltage by preventing water accumulation.

Effect of differences in cell temperature on water distribution in the vicinity of the MPL.-This section discusses the water distribution under the lower temperature conditions in the vicinity of the MPL for the two types of MEA. After observing the ice distribution under the various temperature conditions and observation points, it showed that the water distribution in the vicinity of the MPL can be classified into four types. Schematic diagrams of these four types of ice distributions are shown in Fig. 6. Explanation of these patterns before the presentation of the obtained cryo-SEM images may be helpful to understand the observed results, the four pattern types classified here are termed types A, B, C, and D hereafter. In type A, the ice was observed neither at the MPL/CL interface nor in the pores of the MPL, and the ice distribution under the lands in the MEA made by the GDE method falls under this type at the $70^{\circ} \mathrm{C}$ condition (e.g. Figs. 5c and 5e). In type B, a small amount of ice is observed in the pores of the MPL, and there is no ice layer at the interface between the MPL and CL. Type $\mathrm{C}$ is similar to type $\mathrm{B}$, but larger amounts of ice are observed in the pores of the MPL. In type D, an ice layer is observed at the MPL/CL interface while there is no ice inside the MPL. The ice distribution under the channels in the MEA made by the decal transfer method applies to this type under the $70^{\circ} \mathrm{C}$ condition (Figs. 5b and 5f). For the $\mathrm{CL}$, there were no obvious differences in the internal ice distribution in any of the cases.

Figure 7 shows examples of images of the type B ice distribution after the $35^{\circ} \mathrm{C}$ operation. Figures $7 \mathrm{a}$ and $7 \mathrm{~b}$ are images of the MPL/CL 

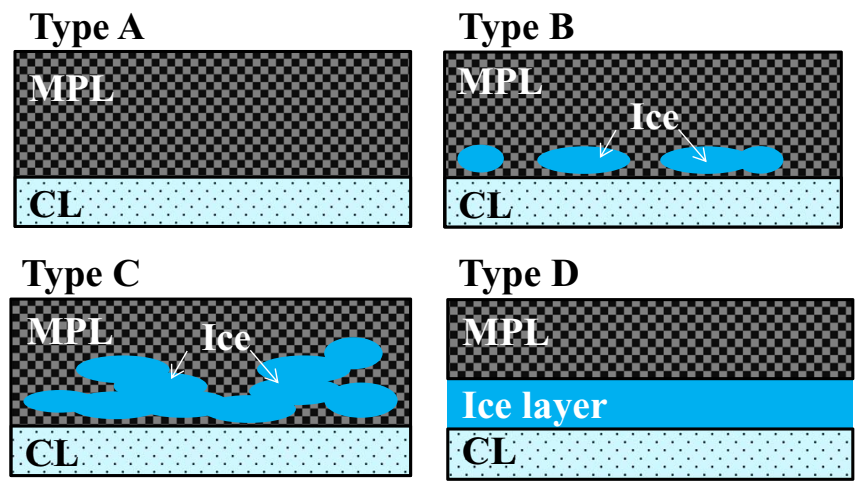

Figure 6. Schematic diagrams of the ice distributions in the vicinity of the MPL. Type A: No ice layer at the MPL/CL interface, no ice in the pores of the MPL. Type B: No ice layer at the MPL/CL interface, small amounts of ice in the pores of the MPL. Type C: No ice layer at the MPL/CL interface, much ice in pores of the MPL. Type D: Ice layer at the MPL/CL interface, no ice in the pores of the MPL.

interfaces: (a) is under a channel of the MEA made by the GDE method, and (b) is under a land of MEA made by the decal transfer method. Figures 7c and 7d are images of the inside of the MPL: the place observed (under a channel/land) and the fabrication methods of the MEA are the same as in (a) and (b). A small amount of ice is everywhere observed inside the MPL, while no ice is observed at the interface. In Fig. 7d some amount of distributed ice is visible, different from our previous result with an MEA manufactured by a different company. ${ }^{18}$ In that previous study, there was no ice inside the MPL after the $35^{\circ} \mathrm{C}$ operation at any of the observation points. Since the water vapor transport capacity through the MPL driven by the saturation pressure gradient ${ }^{5}$ at the $35^{\circ} \mathrm{C}$ operation is smaller than that at the $70^{\circ} \mathrm{C}$ operation, such a difference in physical properties among manufacturing companies may sensitively affect the water condensation in the MPL. The type B ice distribution suggests that a part of the vapor passing through the MPL condenses and accumulates in the MPL when the vapor transport capacity across the MPL is insufficient, compared to the production rate. This ice distribution may be independent of the current density as suggested by Owejan et al.: the higher current density increases the temperature gradient across the MPL, allowing a larger vapor transport flux. ${ }^{5}$ Since the images for both types of MEA are similar, such a condensation phenomenon may
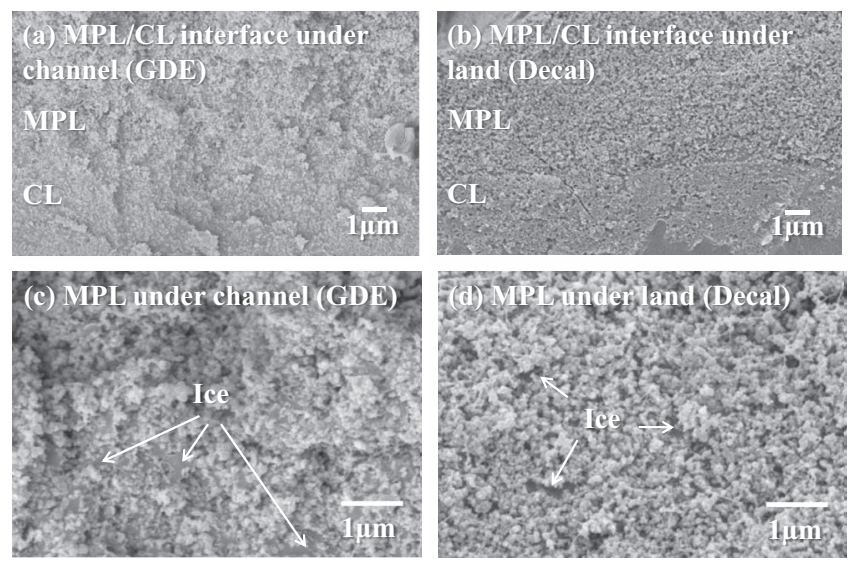

Figure 7. Cryo-SEM images of the ice distribution in the vicinity of the MPL in type $\mathrm{B}$ (Fig. 6 ; the $35^{\circ} \mathrm{C}$ operation). (a) MPL/CL interface under a channel made by the GDE method, (b) MPL/CL interface under a land made by the decal transfer method, (c) inside the MPL under a channel of the MEA made by the GDE method, and (d) inside the MPL under a land of the MEA made by the decal transfer method.
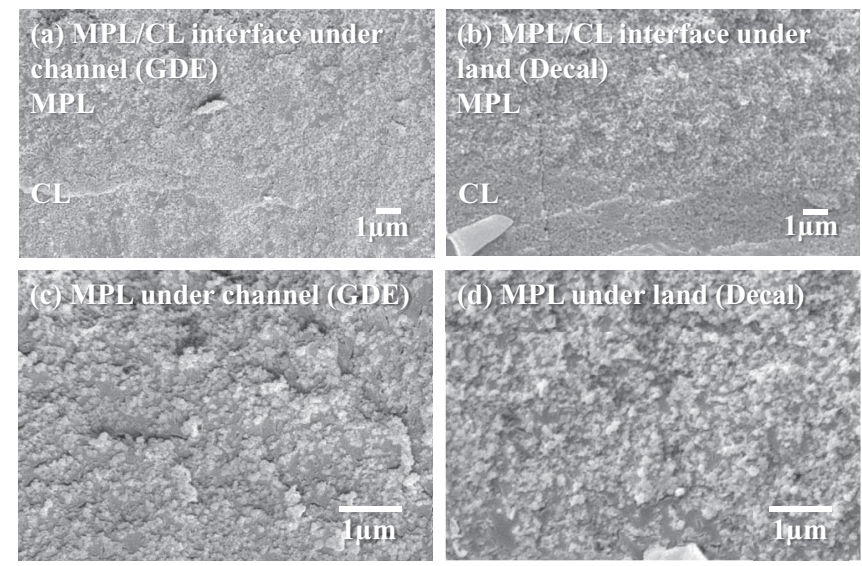

Figure 8. Cryo-SEM images of the ice distribution in the vicinity of the MPL in type $\mathrm{C}$ (Fig. 6 ; the $5^{\circ} \mathrm{C}$ operation). (a) MPL/CL interface under a channel made by the GDE method, (b) MPL/CL interface under a land made by the decal transfer method, (c) inside the MPL under a channel of the MEA made by the GDE method, and (d) inside the MPL under a land of the MEA made by the decal transfer method.

occur in the same manner for the two different fabrication methods at firmly contacting MPL/CL interface locations.

Figure 8 shows examples of images of the type $\mathrm{C}$ ice distribution. Figures $8 \mathrm{a}$ and $8 \mathrm{~b}$ are images of the MPL/CL interfaces, and Figs $8 \mathrm{c}$ and $8 \mathrm{~d}$ are images inside the MPL; the observed position and fabrication method of the MEA are the same as in Figs 7a-7d. These images are observations after the $5^{\circ} \mathrm{C}$ operation, the condition with the smallest vapor transport capacity over the MPL in this study. The type $\mathrm{C}$ ice distribution is somewhat similar to that of type $\mathrm{B}$, but larger amounts of ice are observed in the pores of the MPL, and the original porous structure is lost in Figs. 8c and 8d. The type $\mathrm{C}$ ice distribution suggests that a large amount of vapor is condensed before passing through the MPL because of an insufficient vapor transport rate due to the very low vapor transport capacity. This pattern of condensation may be similar regardless of the MPL/CL interface structure, except for the case under channels with the decal method, when a thick ice layer is formed at the interface.

Relation between the water accumulation in the vicinity of the MPL and cell performance.-This section discusses the effect of water accumulation in the vicinity of the MPL on cell performance based on the observed results shown above. Table I summarizes the states of the ice distributions in the vicinity of the MPL classified by the places of accumulation, operating conditions, and fabrication methods of cathode MPL/CL interface. In the $70^{\circ} \mathrm{C}$ operation (as per Fig. 5), the type A ice distribution is observed in the MEA made by the GDE method under both channels and lands. The ice distribution of the MEA made by the decal transfer method is different at different observation points: type A under the lands and type D under the channels. In the $35^{\circ} \mathrm{C}$ operation (Fig. 7), the type $\mathrm{B}$ ice distribution is observed in the MEA made by the GDE method under both channels and lands. The ice distribution of the MEA made by the decal transfer method is type B under the lands and type D under the channels. In the $5^{\circ} \mathrm{C}$ operation (Fig. 8), the ice distribution in the MEA made by the GDE method is type $\mathrm{C}$ at all observation points while that of the MEA made by the decal transfer method is type $\mathrm{C}$ under the lands and type $\mathrm{D}$ under the channels.

In the $70^{\circ} \mathrm{C}$ operation, the oxygen gain of the MEA using the GDE method is lower than that using the decal transfer method as shown in Fig. 2d. There is no ice at the MPL/CL interface made by the GDE method, while there is an ice layer at the interface under the channels made by the decal transfer method. In the MPL, there is no ice at either structures at this temperature condition. There is no ice in the MPL even in the high current density region, suggesting that the water 
Table I. Ice distribution classifications as shown in Fig. 6 at the location in the vicinity of the MPL for the position under lands or channels, operating conditions, and fabrication methods of the cathode MPL/CL interface.

$70^{\circ} \mathrm{C}$

GDE method

Decal method

Channel

A

D $35^{\circ} \mathrm{C}$

Channel Land

$5^{\circ} \mathrm{C}$

Channel Land

distribution inside the MPL does not depend on the current density. Since the operating conditions and water distributions inside the MPL are similar in both types of MEA, the water distribution inside the GDL and gas flow channels may also be considered to result in similar water distributions regardless of the interface structures. From these results, the difference in oxygen gains at the $70^{\circ} \mathrm{C}$ operation appear to be caused by the accumulation of water at the interface under channels. It may be concluded that the increase in concentration overvoltage is induced by limiting the supply of oxygen to the reaction area due to the water accumulation at the interface.

The oxygen gains in both types of MEA increase when the cell temperature becomes lower. The amount of ice inside the MPL also increases regardless of the interface structures as the cell temperature becomes lower. This water accumulation can be considered as one of the causes of the increase in concentration overvoltage at lower temperatures. The supply of oxygen to the reaction area is limited by the increase in condensed water in the MPL due to the low temperature, and results in the increase in oxygen gains. In addition, the lower temperature conditions also induce the increase in concentration overvoltage caused by the water accumulation inside the GDL and gas flow channel region together with the water accumulation in the MPL.

As discussed in the previous section, the differences in cell voltage shown in Fig. 2c are considered to be caused by the differences in concentration overvoltage between the MEA using the GDE and decal methods. At the $70^{\circ} \mathrm{C}$ operation, the voltage difference is small when liquid water production is little. This voltage difference increases as the cell temperature becomes lower at the high current densities, when larger amount of water accumulates. Here, in each condition, the ice distribution inside the MPL was similar as shown in Figures 7 and 8 , regardless of the fabrication method of the cathode interface. In the vicinity of MPL under lands, ice distribution patterns are also similar in both types of MEA as noted in Table I. The ice distribution at the MPL/CL interface under channels is the only difference in the two types of MEA. It may then be concluded that the larger amount of accumulated water at the interface under channels appears to be the cause in the voltage differences between the two different MEAs. In these experiments, there are no significant differences in the thickness of the ice layers at the interface for the different temperature conditions. This may suggest that accumulation of water expands in the in-plane direction of the interface, and that the area covered by liquid water increases at the lower temperatures and higher current densities, resulting in the increased concentration overvoltage, while further investigation is required to be able to discuss details of this. The suppression of water accumulation at the MPL/CL interface made by the GDE method contributes to prevent flooding, and its effect becomes more significant under lower temperatures and higher current density conditions.

\section{Conclusions}

This paper investigates the effects of differences in MPL/CL interface structure on the PEFC performance based on observations of the water distribution in the vicinity of the cathode side MPL. The major conclusions may be summarized as follows:

1. The MEA using the GDE method achieves a higher cell voltage than that using the decal transfer method at high current densities. The difference in the cell voltages between the two types of MEA

$\begin{array}{llll}\text { B } & \text { B } & \text { C } & \text { C } \\ \text { D } & \text { B } & \text { D } & \text { C }\end{array}$

increases as cell temperature decreases. The performance of the cell using the GDE method does not deteriorate significantly, differently from that using the decal transfer method, particularly in the low temperature operation. The oxygen gains suggest that the GDE method prevents the increasing concentration overvoltage and this helps maintain the cell performance under lower temperatures and higher current density conditions.

2. Cryo-SEM observations show that water does not accumulate at the MPL/CL interface with the MEA made by the GDE method. However, in the MEA made by the decal transfer method, water does accumulate at the interface gaps between the MPL and CL under the channels. This appears to be the cause of the differences in the cell performance with the two fabrication methods.

3. As the cell temperature decreases, lager amounts of water accumulate inside the MPL, similarly with both interface fabrication methods. As the only difference in the water distribution between the two types of MEA is the water amount in the interface, it may be concluded that the significant voltage difference between the two types of MEA is caused by accumulation of water at the interface. The suppression of water accumulation by the MPL/CL interface made by the GDE method becomes more effective under extreme flooding conditions at lower temperatures.

4. At normal operating temperatures there is no water in the MEA, suggesting that the water is transported through the MPL as vapor at this temperature condition. At lower temperature conditions, water amounts inside the MPL increase similarly with the two types of MEA as the temperature becomes lower. The water accumulation in the MPL together with the water accumulation at the interface may be a cause of the decreased performance at lower temperatures.

\section{Acknowledgments}

The authors thank K. Okada and H. Nishikawa (undergraduate students of Hokkaido University) for help with the experiments and the cryo-SEM observations. The cryo-SEM observations were conducted at the Electron Microscope Laboratory, Research Faculty of Agriculture, Hokkaido University. This research was supported by JSPS KAKENHI grant Number 261599.

\section{References}

1. A. Z. Weber and J. Newman, J. Electrochem. Soc., 152, A677 (2005)

2. U. Pasaogullari, C.-Y. Wang, and K. S. Chen, J. Electrochem. Soc., 152, A1574 (2005).

3. J. T. Gostick, M. A. Loannidis, M. W. Fowler, and M. D. Prizker, Electrochem. Commun., 11, 576 (2009).

4. Z. Lu, M. Daino, C. Rath, and S. G. Kandlikar, Int. J. Hydrogen Energy, 35, 4222 (2010).

5. J. P. Owejan, J. E. Owejan, W. Gu, T. A. Trabold, T. W. Tighe, and M. F. Mathias, J. Electrochem. Soc., 157, B1456 (2010).

6. F. E. Hizir, S. O. Ural, E. C. Kumbur, and M. M. Mench, J. Power Sources, 195, 3463 (2010).

7. A. R. Kalidindi, R. Taspinar, S. Lister, and E. C. Kumbur, Int. J. hydrogen Energy, 38, 9297 (2013).

8. I. V. Zenyuk, E. C. Kumbur, and S. Lister, J. Power Sources, 241, 379 (2013).

9. H. Bajpai, M. Khandelwal, E. C. Kumbur, and M. M. Mench, J. Power Sources, 195, 4196 (2010).

10. T. Swamy, E. C. Kumbur, and M. M. Mench, J. Electrochem. Soc., 157, B77 (2010).

11. X. G. Yang, F. Y. Zhang, A. L. Lubawy, and C. Y. Wang, Electrochem. Solid-State Lett., 7, A408 (2004). 
12. J. H. Nam, K. Lee, G. Hwang, and C. Kim, J. Heat and Mass Transfer, 52, 2779 (2009).

13. T. Sasabe, P. Deevanhxay, S. Tsushima, and S. Hirai, J. Power Sources, 196, 8197 (2011).

14. P. Deevanhxay, T. Sasabe, S. Tsushima, and S. Hirai, J. Power Sources, 230, 38 (2013).

15. J. Lee, J. Hinebaugh, and A. Bazylak, J. Power Sources, 227, 123 (2013).

16. C. Hartnig, I. Manke, R. Kuhn, S. Kleinau, J. Goebbels, and J. Banhart, J. Power Sources, 188, 468 (2009).
17. M. C. Hatzell, A. Turthan, S. Kim, D. S. Hussey, D. L. Jacobson, and M. M. Mench, J. Electrochem. Soc., 158, B717 (2011).

18. Y. Aoyama, K. Suzuki, Y. Tabe, and T. Chikahisa, Electrochem. Commun., 41, 72 (2014).

19. Y. Tabe, Y. Aoyama, K. Kadowaki, K. Suzuki, and T. Chikahisa, J. Power Sources, 287, 422 (2015).

20. T. Tanuma and S. Kinoshita, J. Electrochem. Soc., 161, F94 (2014).

21. K. S. S. Naing, Y. Tabe, and T. Chikahisa, J. Power Sources, 196, 2584 (2011). 